\title{
THE OSTEO-INDUCTIVE ACTIVITY OF BONE-MARROW-DERIVED MONONUCLEAR CELLS RESIDES WITHIN THE CD14 POPULATION AND IS INDEPENDENT OF THE CD $34^{+}$POPULATION
}

\author{
D. Henrich ${ }^{*, 1}$, C. Seebach ${ }^{\S, 1}$, R. Verboket ${ }^{1}$, A. Schaible ${ }^{1}$, I. Marzi ${ }^{\S, 1}$ and H. Bonig ${ }^{\S, 2,4}$ \\ ${ }^{1}$ Department of Trauma, Hand and Reconstructive Surgery, Johann-Wolfgang-Goethe University, \\ Frankfurt am Main, Germany \\ ${ }^{2}$ Institute for Transfusion Medicine and Immune Haematology, Johann-Wolfgang-Goethe University, \\ Frankfurt am Main, Germany \\ ${ }^{4}$ DRK-Blutspendedienst Baden-Württemberg-Hessen, Frankfurt am Main, Germany \\ $\S$ These authors contributed equally
}

\begin{abstract}
Bone marrow mononuclear cells (BMC) seeded on a scaffold of $\beta$-tricalcium phosphate $(\beta-\mathrm{TCP})$ promote bone healing in a critical-size femur defect model. Being BMC a mixed population of predominantly mature haematopoietic cells, which cell type(s) is(are) instrumental for healing remains elusive. Although clinical therapies using BMC are often dubbed as stem cell therapies, whether stem cells are relevant for the therapeutic effects is unclear and, at least in the context of bone repair, seems dubious. Instead, in light of the critical contribution of monocytes and macrophages to tissue development, homeostasis and injury repair, in the current study it was hypothesised that BMC-mediated bone healing derived from the stem cell population. To test this hypothesis, bone remodelling studies were performed in an established athymic rats critical-size femoral defect model, with $\beta$-TCP scaffolds augmented with complete BMC or BMC immunomagnetically depleted of stem cells $\left(\mathrm{CD} 34^{+}\right)$or monocytes/macrophages $\left(\mathrm{CD} 14^{+}\right)$. Bone healing was assessed 8 weeks after transplantation. Compared to BMC-augmented controls, when $\mathrm{CD} 14^{-} \mathrm{BMC}$, but not CD34- $\mathrm{BMC}$ were transplanted into the bone defect, femora possessed dramatically decreased biomechanical stability and new bone formation was markedly reduced, as measured by histology. The degree of vascularisation did not differ between the two groups. It was concluded that the monocyte fraction within the BMC provided critical osteo-inductive cues during fracture healing. Which factors were responsible at the molecular levels remained elusive. However, this study marked a significant progress towards elucidating the mechanisms by which BMC elicit their therapeutic effects, at least in bone regeneration.
\end{abstract}

Keywords: Bone marrow mononuclear cells, monocytes, CD14, CD34, bone healing.

*Address for correspondence: Dirk Henrich, Department of Trauma, Hand and Reconstructive Surgery, University Hospital Frankfurt, Theodor Stern-Kai 7, Frankfurt am Main, Germany.

Telephone: +49 6963017110 ......Fax: +496963017108Ｅmail: d.henrich@trauma.uni-frankfurt.de

Copyright policy: This article is distributed in accordance with Creative Commons Attribution Licence (http://creativecommons.org/licenses/by-sa/4.0/).

\section{Introduction}

Large bone defects due to trauma or resections, because of infections or tumours, pose a major problem in orthopaedic and emergency surgery (Dawson and Oreffo, 2008; Kneser et al., 2006). Artificial or natural decellularised matrices, by themselves, do not provide adequate bone healing. Augmentation of such matrices with various autologous cell types provides a potentially powerful solution to this problem. For this purpose, bonemarrow-derived mesenchymal stroma cells (BM-
MSC) can be expanded from autologous bone marrow and, particularly if supplemented with autologous endothelial cells, substantially improve union and bone remodelling (Henrich et al., 2009; Seebach et al., 2010; Usami et al., 2009). The considerable complexity and, hence, cost of such an approach, as well as the long delay until definitive surgical repair, led us to consider more expedient alternatives. BM-derived mononuclear cell (BMC) products, such as the ones used for cardiovascular regeneration after myocardial infarction (Assmus et al., 2002), in conjunction with a synthetic $\beta$-tricalciumphosphate $(\beta-\mathrm{TCP})$ matrix 
are powerful inducers of bone repair (Nau et al., 2016; Seebach et al., 2015). These initial data from an athymic critical-size femur defect rat model are supplemented by promising clinical data on fractures of the proximal humerus (Seebach et al., 2016).

The therapeutic use of BMC is often referred to as stem cell therapy, although immature haematopoietic cells count for the 2-3\% of the BMC population (Henrich et al., 2015; Seebach et al., 2016). In addition, evidence of the therapeutic contribution of these cells, as opposed to their mature progeny, has never been observed. In contrast, monocytes and macrophages are not only markedly more frequent, but play a critical role in tissue development, homeostasis and injury repair (Ogle et al., 2016). These innate immune cells participate in vascular remodelling, stimulation of local stem and progenitor cells and structural repair of tissues, such as muscle and bone (Ogle et al., 2016).

The analysis of the aforementioned athymic rat critical-size defect model showed that, while haematopoietic stem cells were largely dispensable, BMC depleted of monocytes/macrophages were devoid of osteo-inductive properties.

\section{Materials and Methods}

\section{Ethics}

Human BMC were isolated from bone marrow aspirate obtained from the iliac crest of healthy donors. The use of bone marrow samples for research purposes was approved by the local ethics committee (Ethic Committee of the Medicine Department, Johann-Wolfgang-Goethe University, Frankfurt am Main, Germany Project No. 329/10) and written informed consent was obtained from all donors.

\section{Animal care}

All animal experiments were performed in accordance with regulations established by the Johann-WolfgangGoethe University animal care and oversight committee (Project No. F3/20; Regierungspräsidium, Darmstadt, Germany), in conformation with German law. 21 male athymic rats (RH-FOXN1rnu; HarlanWinkelmann, Horst, the Netherlands), 8-10-week old and weighing approximately 250-320 g, were housed 3 to 4 animals per cage, in temperature- $\left(15-21^{\circ} \mathrm{C}\right)$, airflow- and light- (14 h day and $10 \mathrm{~h}$ night) controlled environment, receiving rat chow and water ad libitum. Animal well-being was ascertained daily during the first week after surgery and weekly thereafter.

\section{Isolation and characterisation of BMC}

BMC were isolated from bone marrow aspirate of 5 donors, anti-coagulated with 8-12 iU/mL heparin and $8-12 \% \mathrm{v} / \mathrm{v}$ acid-citrate-dextrose solution $\mathrm{A}$, as previously described (Sorg et al., 2015). Bone marrow was diluted $1: 3$ with phosphate-buffered saline (PBS) and mononuclear cells were isolated by Ficoll ${ }^{\circledR}$ (1.077 g/ $\mathrm{cm}^{3}$, Biochrom, Berlin, Germany) density gradient centrifugation at $800 \times g$ for $20 \mathrm{~min}$ at room temperature. Interphase cells were carefully aspirated and washed twice with $25 \mathrm{~mL}$ PBS (each wash was followed by a centrifugation at $800 \times g$ ). Cells were diluted to a final concentration of $3 \times 10^{6}$ cells $/ \mathrm{mL}$ in PBS.

Monocytes contained in BMC were further characterised with respect to the frequency of inflammatory (IM) vs. anti-inflammatory monocytes (AM). The human IM subset is $\mathrm{CD}^{2} 4^{+} / \mathrm{CD}_{16}{ }^{-}$; an intermediate subset expresses both CD14 and CD16; the $\mathrm{CD} 14^{\text {low }} / \mathrm{CD} 16^{+} \mathrm{AM}$ subset is implicated in regeneration (Ogle et al., 2016)

$5 \times 10^{5}$ BMC were suspended in $100 \mu \mathrm{L}$ PBS and incubated for $30 \mathrm{~min}$ at $4{ }^{\circ} \mathrm{C}$ with $10 \mu \mathrm{L}$ each of mouse anti-human CD14-PerCP-Cy5.5 (clone: M5E2; BD Biosciences, Heidelberg, Germany), mouse anti-human CD16-APC (clone: B73.1 BDBiosciences), mouse anti-human CD34-PE-CF594 (clone: 581; BD-Biosciences) and mouse antihuman CD45-BV510 (clone: HI30; BD Biosciences). Fluorochrome-conjugated isotype identic antibodies served as control (all control antibodies were purchased from BD Biosciences). Dead cells were excluded by counterstaining with viability stain-780 (BD Biosciences). After incubation, cells were washed twice and immediately analysed by flow cytometry (FACSCanto, BD Biosciences). $1 \times 10^{5}$ mononuclear cells were individually acquired based on their forward and side scatter properties. For the evaluation, the first gate was set to exclude defective cells. Next, CD45 ${ }^{+}$cells were displayed in a forwardscattered light (FSC) and side-scattered light (SSC) dot plot. The monocyte fraction was identified by its forward scatter and side scatter properties and concomitant CD14 staining. Frequencies of CD14 ${ }^{+}$ (monocytes) and $\mathrm{CD} 14^{+} / \mathrm{CD} 16^{+}$cells (intermediate and AMs) as well as of CD34 $4^{+}$cells (stem/progenitor cells) were evaluated by subsequent quadrant analysis, as depicted in Fig. 1.

\section{Depletion of $\mathrm{CD}_{14}^{+}$and $\mathrm{CD} 34^{+}$cells from BMC}

$\mathrm{CD}_{14}{ }^{+}$and $\mathrm{CD} 34^{+}$haematopoietic stem cells were depleted using magnetic bead separation technique, according to the manufacturer's instructions (Miltenyi Biotec, Bergisch-Gladbach, Germany). Briefly, $1 \times 10^{7}$ BMC were incubated with $20 \mu \mathrm{L}$ antihuman CD14 magnetic beads or anti-human CD34 magnetic beads at $4{ }^{\circ} \mathrm{C}$ for $15 \mathrm{~min}$. After washing with MACS-buffer, cells were resuspended in $500 \mu \mathrm{L}$ MACS-buffer and applied to a LD-column placed in a magnetic field. The flow-through was collected, washed once with PBS and cell number was determined. Efficacy of depletion was assessed by flow cytometry. A fluorescein isothiocyanate 1 (FITC)-coupled mouse anti-human CD14 monoclonal antibody (clone M5E2; BD-Biosciences) and a FITCcoupled mouse anti-human CD34 antibody (clone 581; BD-Biosciences) were used to determine the depletion efficiency of the BMC preparation in parallel stainings. 


\section{Seeding of cells to scaffolds}

BMC, BMC depleted of CD14-expressing cells (BMC-CD14) or BMC depleted of CD34-expressing cells (BMC-CD34) were seeded on $\beta$-TCP scaffolds (size 0.7-1.4 mm; Chronos, DePuy Synthes), as previously described (Henrich et al., 2015). Scaffold granules were placed in a dense monolayer in the wells (area $=200 \mathrm{~mm}^{2}$ ) of a 24-well plate (Nunc, Wiesbaden, Germany) using sterile forceps. $1 \times 10^{6}$ $\mathrm{BMC}$ in $350 \mu \mathrm{L}$ PBS were carefully dripped onto each scaffold, followed by $10 \mathrm{~min}$ incubation at $37^{\circ} \mathrm{C}$. Total cell number was identical in all three experimental groups. Subsequently, medium containing nonadherent cells was removed and dripped once again onto the biomaterials, followed by incubation, as indicated above. This procedure was performed twice.

\section{Bone defect model}

The femur critical-size defect was induced as previously described (Seebach et al., 2010; Seebach et al., 2015). In detail, rats were anaesthetised by intraperitoneal administration of $2 \mathrm{~mL}$ of $100 \mathrm{mg} /$ mL Ketavet (Zoetis, Florham Park, NJ, USA) + 20 mg/ $\mathrm{mL}$ Rompun (Bayer, Leverkusen, Germany). The right hindlimb of the rat was shaved and aseptically cleaned. A lateral longitudinal incision over the femur was made. The fascia was cut and the muscles were bluntly separated between the musculus quadriceps femoris and the hamstrings. A 5-holelocking compression plate (Miniplate Lockingplate LCP Compact Hand 1.5 straight, DePuy Synthes) was placed on the surface of the femoral shaft. 4 screws fixed the plate to the bone. Afterwards, the bone cortex was cut by a Gligli saw (RISystems, Davos, Switzerland) and a bone defect of 5-6 mm was created in the midshaft around the middle hole of the plate. The defects were randomly filled with $100 \mu \mathrm{L} \beta$-TCP scaffold seeded with BMC (group 1, $n=7$ ), BMC-CD14 (group 2, $n=7$ ) or BMC-CD34 (group 3, $n=7$ ). Finally, the wound over the graft was closed again by assembling of the musculi vastus lateralis and biceps femoris and adapting of the wound margins with continuous subcutaneous stitches using a 4/0-monofilament nylon suture. Animals had free access to food and water containing opioids for the first $5 \mathrm{~d}$ and they were monitored daily for post-operative morbidity. 8 weeks postsurgery, the animals were painlessly killed by an overdose of pentobarbital (500 mg/kg body weight intraperitoneally) and weighed. Then, femora were dissected and all bones were examined, macro- and microscopically, for signs of infection. All implants fixations were checked by researches blinded to the treatment and only in cases where all screws remained firmly tightened was the animal included in further evaluations. Bones were stored at $4{ }^{\circ} \mathrm{C}$ in $70 \%$ ethanol until biomechanical testing (within $48 \mathrm{~h}$ after resection). After biomechanical testing, bones were wrapped in pre-wetted gauze and stored at $-80{ }^{\circ} \mathrm{C}$ until further processing.

\section{Biomechanical characterisation}

Biomechanical properties of the femur's defect site were measured by a destructive 3-point bending procedure using a material testing machine (Zwickiline Z5.0; Zwick-Roell, Ulm, Germany). The "bending until failure" was performed by lowering a bar onto the femur, using a constant deflection speed of $0.1 \mathrm{~mm} / \mathrm{s}$. Load and deflection were continuously recorded. Ultimate load and stiffness (slope of the elastic deformation part of the load/deformation curve) were calculated using the Testexpert-II software (Zwick-Roell).

Assessment of callus formation, bone maturation, vascularisation and inflammatory cells

Callus formation and bone maturation were assessed by histomorphometric analysis of Movatpentachrome- and osteocalcin-immunostained decalcified sections taken from the bone defect.

For histological evaluation of bone maturation, bones were carefully defrosted and fixed for $20 \mathrm{~h}$ in $10 \%$ Zinc-Formal-Fixx ${ }^{\mathrm{TM}}$ (Thermo Fisher Scientific), followed by decalcification for $14 \mathrm{~d}$ in $0.25 \mathrm{M}$ Trizma ${ }^{\circledR}$ base (Sigma-Aldrich) and $10 \%$ EDTA (Sigma-Aldrich), pH 7.4. Decalcified bones were paraffin-embedded and $3 \mu \mathrm{m}$-thick longitudinal sections were cut. Movat pentachrome staining of paraffin-embedded histological slides was performed as published by Garvey et al. (1986), using a staining kit according to the manufacturer's instructions (Morphisto, Frankfurt, Germany).

Callus maturation was measured by immunohistochemistry through detection of osteocalcin, vascularisation through staining of $\alpha$-smooth muscle actin ( $\alpha$-SMA). The sections were incubated with monoclonal mouse anti-rat osteocalcin (1 h, $10 \mu \mathrm{g} / \mathrm{mL}, 75 \mu \mathrm{L} /$ slide; clone 1A4, Abcam) or monoclonal mouse anti-rat $\alpha$-SMA (1 h, $2 \mu \mathrm{g} / \mathrm{mL}, 75 \mu \mathrm{L} / \mathrm{slide}$; clone OC4-30, Abcam). As secondary antibody, a polyclonal HRP-conjugated anti-mouse IgG (rat Simple Stain ${ }^{\mathrm{TM}} \mathrm{MAX}$ PO, Nichirei Biosciences Inc., Tokyo, Japan) was applied for 30 min followed by incubation with 3-amino-9ethylcarbazole (AEC, Sigma-Aldrich) following the manufacturer's instructions. Finally, a counterstain with haematoxylin was performed. The samples were analysed by an independent observer blinded to the groups set-up. All slides were analysed using light microscopy (Axioobserver Z1, Zeiss; Biorevo BZ-9000, Keyence, Neu-Isenburg, Germany) in combination with a computer-supported imaging picture analysis system (Axiovision, Zeiss; Software, Keyence). High resolution images depicting the whole defect zone were created by automated stitching of multiple single frames covering the whole defect using the software BZ-II Analyzer (Keyence).

New bone formation, osteocalcin- or $\alpha$-SMApositive areas were analysed in the defect site using the software ImageJ (Web ref. 1). Since intensity of osteocalcin staining in the various tissues/ biomaterials did not allow for fully automated image 
b

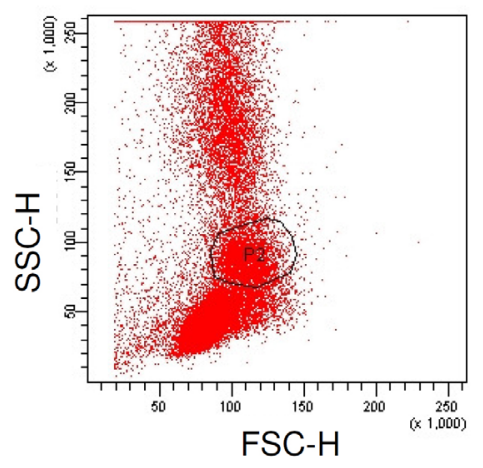

d

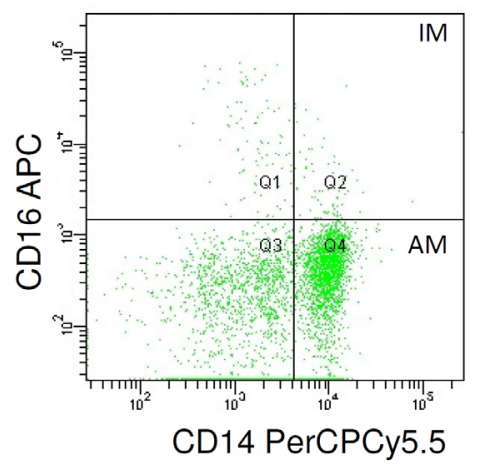

f

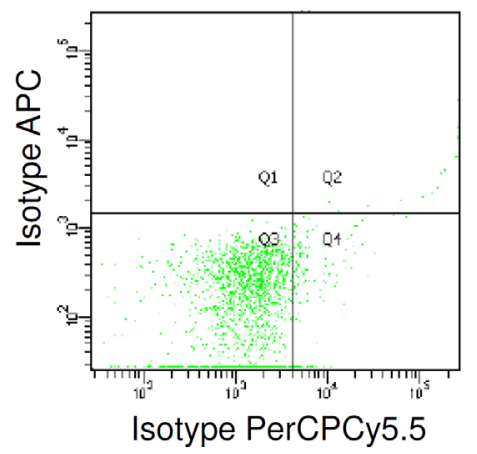

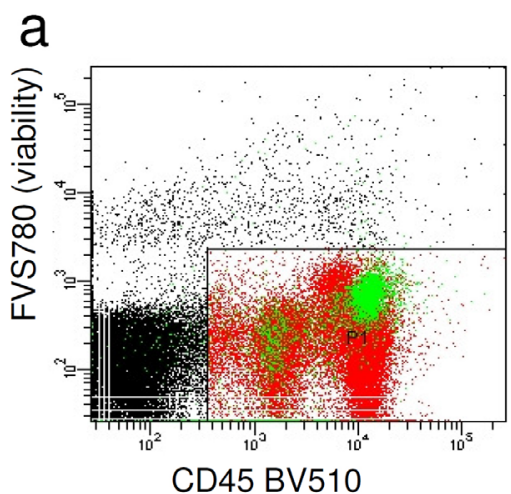

C

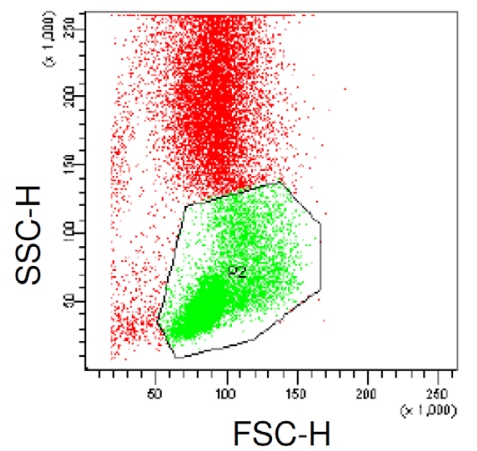

e

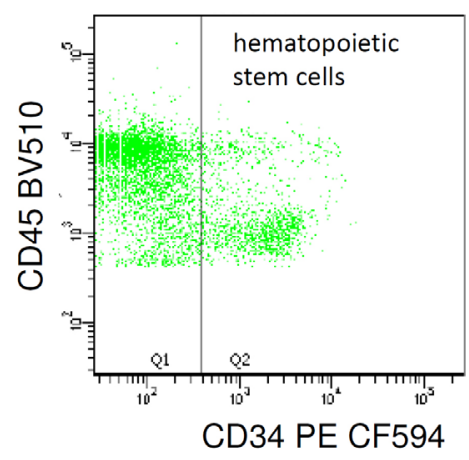

9

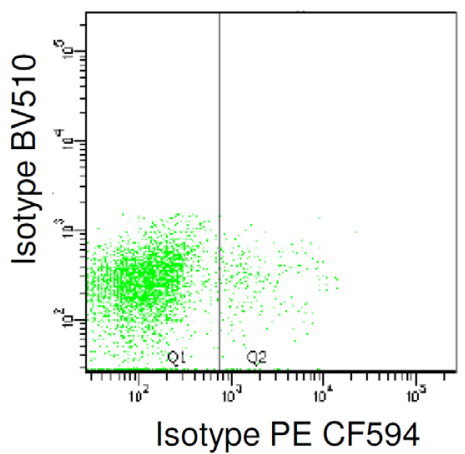

Fig. 1. Enumeration of $\mathrm{IM}\left(\mathrm{CD} 45^{+}, \mathrm{CD} 14^{+}, \mathrm{CD} 16^{-}\right)$and $\mathrm{AM}\left(\mathrm{CD} 45^{+}, \mathrm{CD} 14^{+}, \mathrm{CD} 16^{+}\right)$in human $\mathrm{BMC}$ preparations by multicolour flow cytometry. (a) First gate is set on viable CD45 ${ }^{+}$cells. (b,c) Gating of monocyte population and mononuclear cell population according to their FSC-SSC properties. (d) Analysis of CD16 expression on CD14 cells. IM are located in Q2, AM in Q4. (e) Assessment of CD34 stem cells. $\mathrm{CD}_{4} 4^{+}$cells are located in Q2. (f,g) Isotype control, cells within the monocyte gate and the mononuclear cell gate. 
analysis, area of osteocalcin-positive new bone tissue was marked by an independent observer using the polygon tool of Image J and the relative osteocalcinpositive area of the entire defect zone was calculated.

Infiltration of neutrophils, as a sign of inflammatory processes, was assessed on histological slides by chloroacetate-esterase (CAE) staining (Naphtol AS-D Chloroacetate-esterase, Sigma-Aldrich), following the manufacturer's instructions. Neutrophil infiltration into the defect was judged in a qualitative manner by an independent researcher blinded to the groups set-up.

\section{Statistics}

Results are presented as box plots of the median in diagrams or as mean and standard deviation in the description of the results. For comparisons between the groups, a non-parametric Kruskal-Wallis test with Bonferoni-Holm corrected Conover-Iman post-hoc analysis using the statistical software Bias 11.02 (Epsilon-Verlag, Darmstadt, Germany) was performed. $p<0.05$ indicated statistical significance. $p$-values between 0.05 and 0.1 were rated as a statistical trend.

\section{Results}

\section{Animal care, characteristics of BMC, depletion efficacy}

One animal was excluded in group 3 (BMC-CD34) due to pin loosening; thus, total number of animals in that group was 6. a

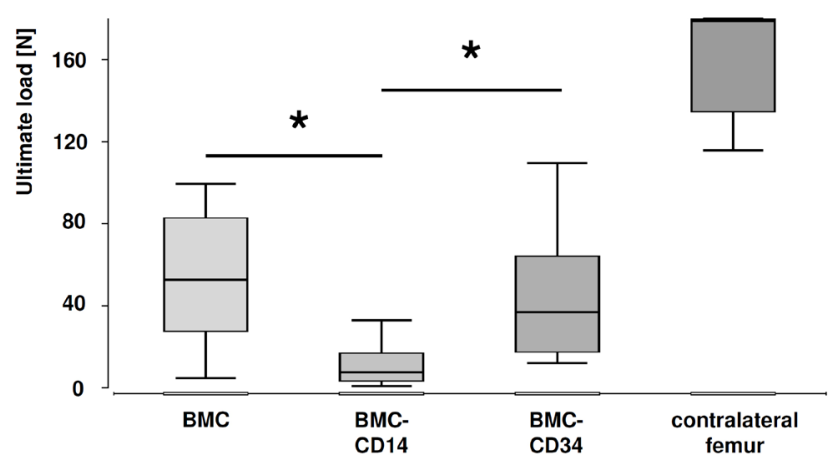

b

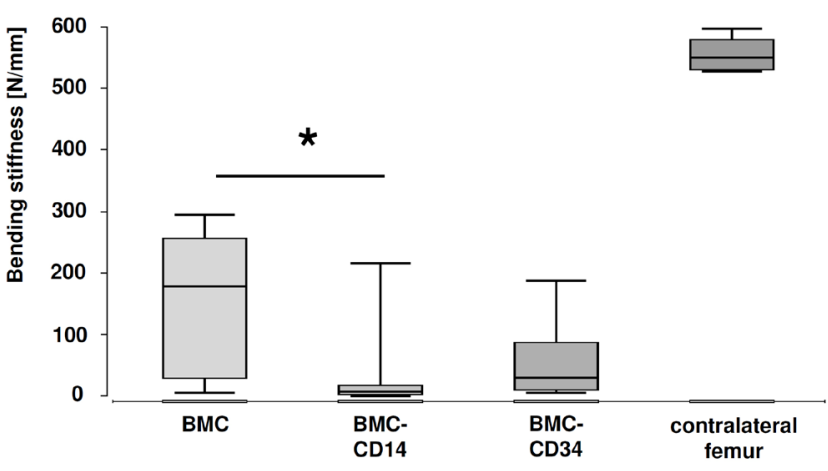

C

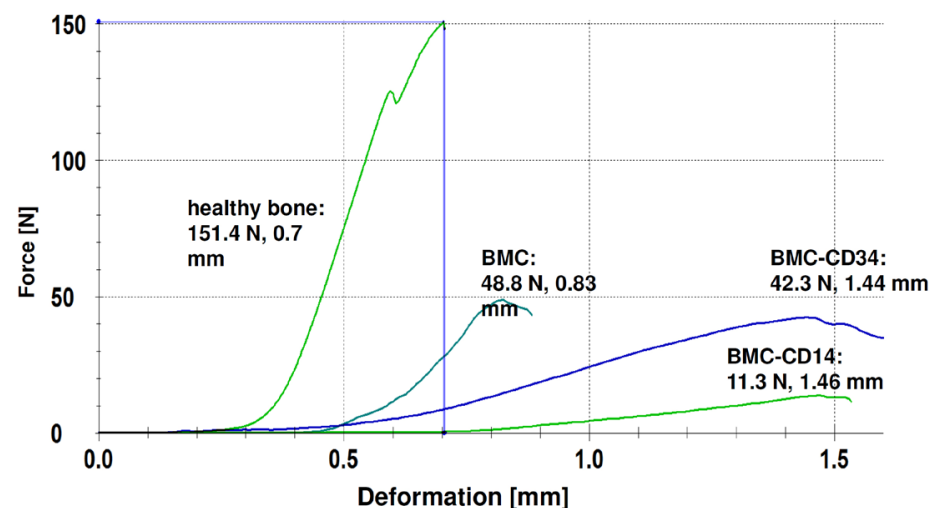

Fig. 2. (a) Ultimate load and (b) bending stiffness of the defect zone transplanted with either complete BMC, BMC-CD14 or BMC-CD34. Biomechanical properties of the defect zone were measured by threepoint bending test 8 weeks after transplantation. (c) Representative force/deformation curves of femora obtained from animals that received BMC, BMC-CD14 or BMC-CD34. The force/deformation curve of a healthy rat femur is shown for comparison. Peak of the curves indicate the ultimate load of the bone samples. ${ }^{*} p<0.05$ 
CD14 depletion reduced the monocyte content from $13.8 \pm 8.8 \%$ (BMC) to $2.9 \pm 1.6 \%$ (BMC-CD14), with a mean monocytes depletion efficacy of $78.5 \%$. The mean content of CD34 ${ }^{+}$cells was reduced from $4.3 \pm 1.8 \%$ to $0.8 \pm 0.6 \%$ after depletion (BM-CD34), with a depletion efficacy of $81.4 \%$.

The distribution of the inflammatory $\left(\mathrm{CD} 14^{+} \mathrm{CD} 16^{-}\right)$ and anti-inflammatory $\left(\mathrm{CD} 14^{+} \mathrm{CD} 16^{+}\right)$subtypes was assessed in additional bone marrow samples $(n=5)$ not used for the animal experiments. In BMC, the mean frequencies of inflammatory monocytes, antiinflammatory subtype and stem/progenitor cells were
$7.9 \pm 2.2 \%, 1.0 \pm 1.5 \%$ and $4.9 \pm 2.1 \%$, respectively (Fig. 1).

\section{Biomechanics}

A randomised selection of heathy bone taken from the rabbits' contralateral side resisted forces up to $161.4 \pm 24.5 \mathrm{~N}(n=8)$, whereas bone with a $\beta$-TCP scaffold, but no cell augmentation offers no resistance (Nau et al., 2016; Seebach et al., 2015). Bone ultimate load was largely reconstituted in $\beta$-TCP + BMC-augmented bone (54.7 $\pm 34.1 \mathrm{~N}) \cdot \beta$-TCP + BMC-CD34-augmented bone showed modestly a

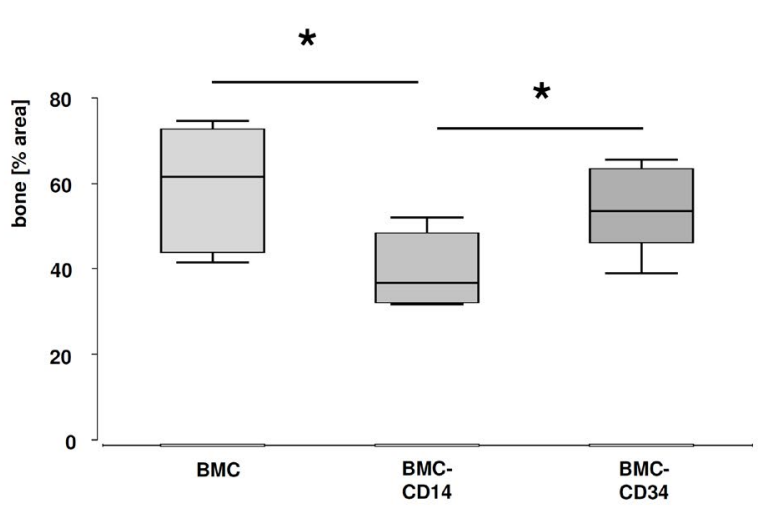

C

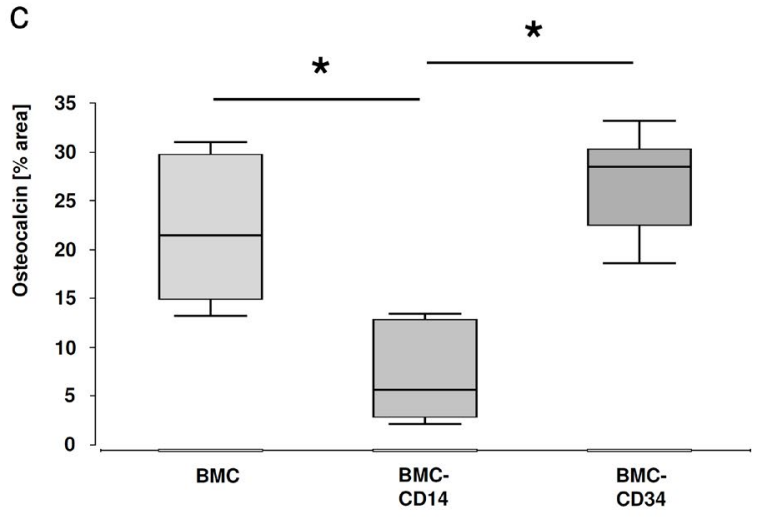

b

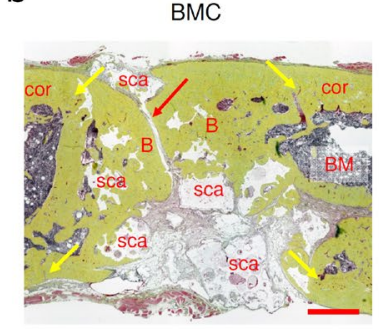

BMC-CD34

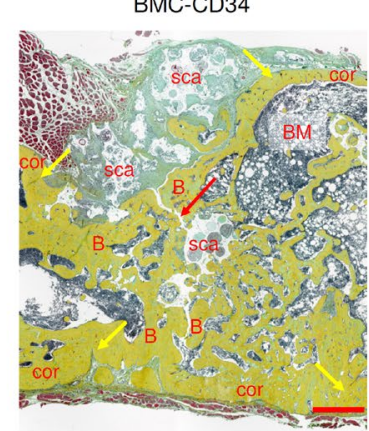

d

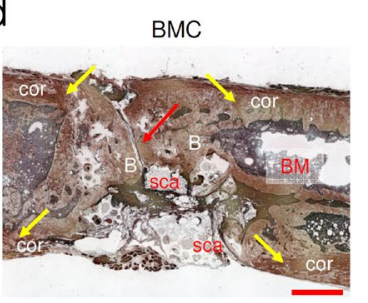

$B M C-C D 34$

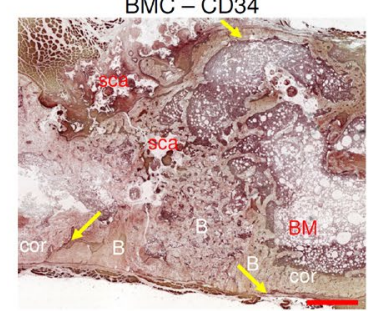

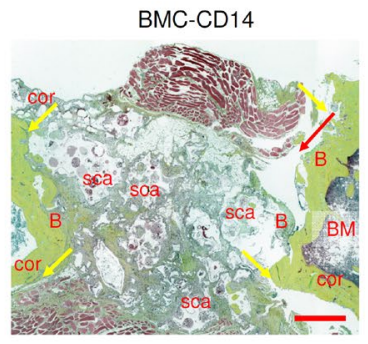


reduced (1.2-fold) resistance $(43.9 \pm 34.8 \mathrm{~N}, p=0.43 v$ s. $\mathrm{BMC})$, while $\beta$-TCP + BMC-CD14-augmented bone offered significantly, 5.1-fold, decreased resistance (10.7 $\pm 11.5 \mathrm{~N}, p=0.03$ vs. BMC).

Accordingly, bending stiffness was 3.2-fold higher in the BMC group $(115 \pm 116 \mathrm{~N} / \mathrm{mm})$ as compared to femora extracted from animals receiving BMC-CD14 $(36.5 \pm 78.6 \mathrm{~N} / \mathrm{mm}, p=0.02)$, whereas a not significant, 2.2-fold decrease was measured in animals receiving BMC-CD34 (52.0 \pm 67.7 N/mm, $p=0.18)$ (Fig. 2).

\section{New bone formation and bone maturation}

New bone formation was assessed based on histomorphometric evaluation of Movatpentachrome-stained slides. $59.4 \pm 14.8 \%$ of the bone defect area was filled with newly formed bone in the presence of the BMC-augmented $\beta$-TCP scaffold, compared to $54.5 \pm 10.1 \%(p=0.66)$ and $42.5 \pm 11.3 \%(p=0.04)$ with BMC-CD34- and BMCCD14-augmented $\beta$-TCP scaffolds, respectively (Fig. 3).

Maturation of the newly formed bone tissue in the defect zone was assessed by osteocalcin immunostaining. Osteocalcin-positive area covered the $22.0 \pm 7.5 \%$ of the bone defect area, in animals treated with the $\beta$-TCP scaffold seeded with BMC, compared to $26.9 \pm 5.0 \%$ with the BMCCD34-augmented $\beta$-TCP scaffold $(p=0.39)$. $\beta$-TCP

a

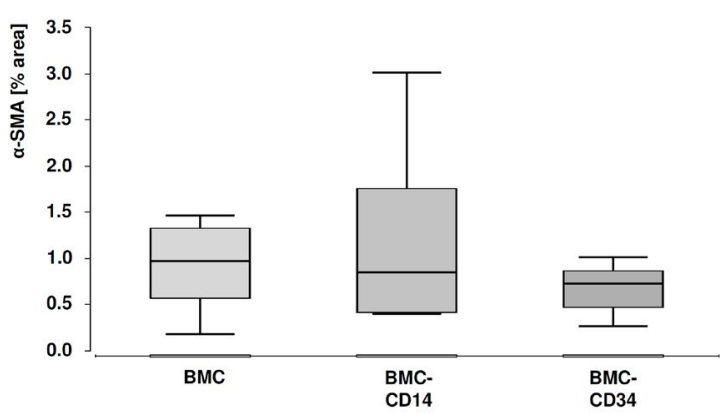

Fig. 4. (a) $\alpha$-SMA-positive blood vessels within the bone defect in animals transplanted with either complete BMC or BMC-CD14 or BMC-CD34, 8 weeks after surgery. Percentage of $\alpha$-SMApositive area in the defect zone was determined by histomorphometry. (b) Representative images of $\alpha$-SMA stainings at low magnification (left row) and in detailed view (right row). Representative isotype control indicating the specificity of the staining is indicated as $\alpha$-SMA isotype control, with unstained vessel structures marked with arrows. Blue arrows indicate $\alpha$-SMA-positive blood vessels. Red arrows indicate probable fracture due to prior biomechanical testing. Yellow arrows indicate edges of the original defect. Red bars represent $1 \mathrm{~mm}$ (upper row) and $100 \mu \mathrm{m}$ (lower row).
+ BMC-CD14-augmented bone showed significantly decreased (3-fold) osteocalcin positivity $(7.1 \pm 4.9 \%$, $p=0.004)$ as compared to animals treated with the BMC-augmented $\beta$-TCP scaffold (Fig. 3).

\section{Vascularisation}

The vascularisation within the defect zone was assessed by $\alpha$-SMA staining, with similar results in all groups (Fig. 4).

\section{Inflammation}

Neutrophil infiltration, as a sign of ongoing inflammatory processes, was assessed in the defect zone. Significant neutrophil infiltration was not observed in any group. CAE-positive cells were observed in the bone marrow, but the amount was comparable to healthy bones (Fig. 5).

\section{Discussion}

The contribution of monocytes $\left(\mathrm{CD} 14^{+}\right)$and haematopoietic stem cells $\left(\mathrm{CD} 34^{+}\right)$to the therapeutic effect of BMC in large bone defect healing was analysed. Compared to non-depleted BMC preparations, relevant bone healing parameters were markedly attenuated when the CD14 ${ }^{+}$cell fraction was depleted from the BMC preparation.

b

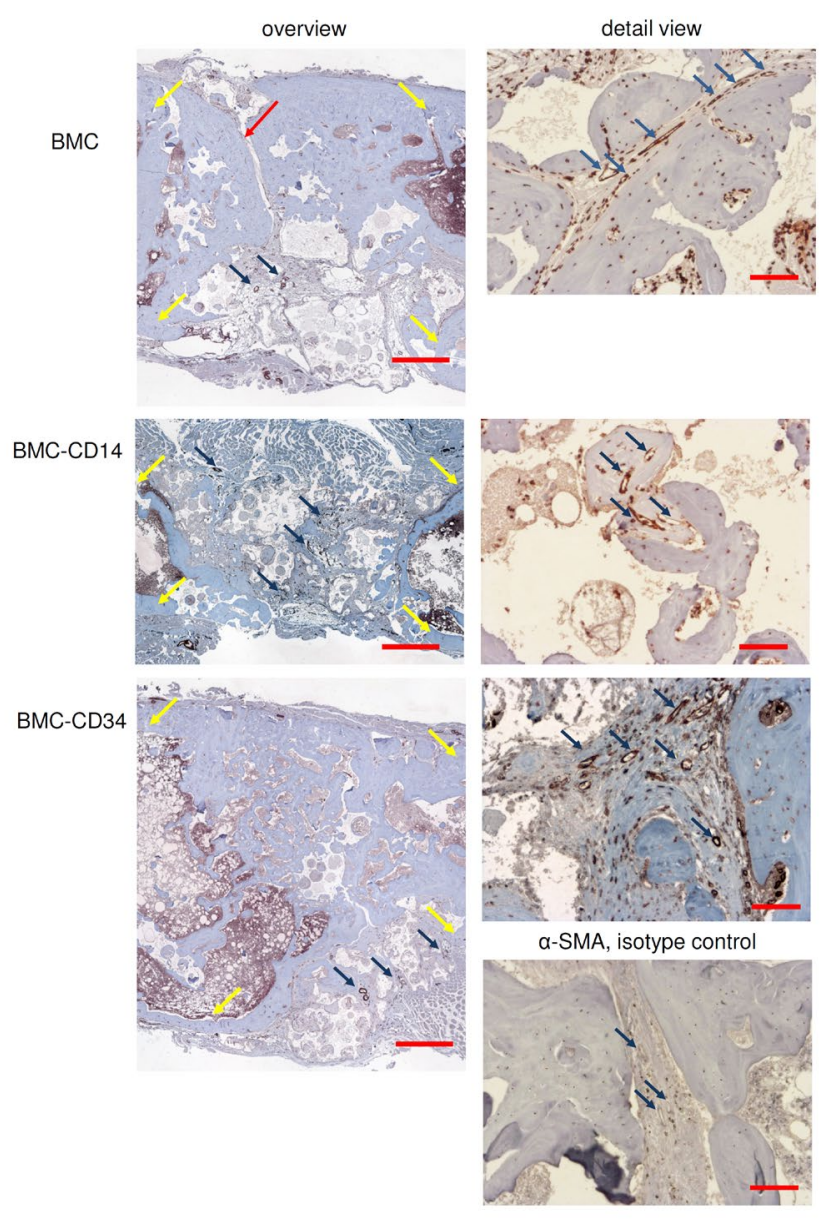




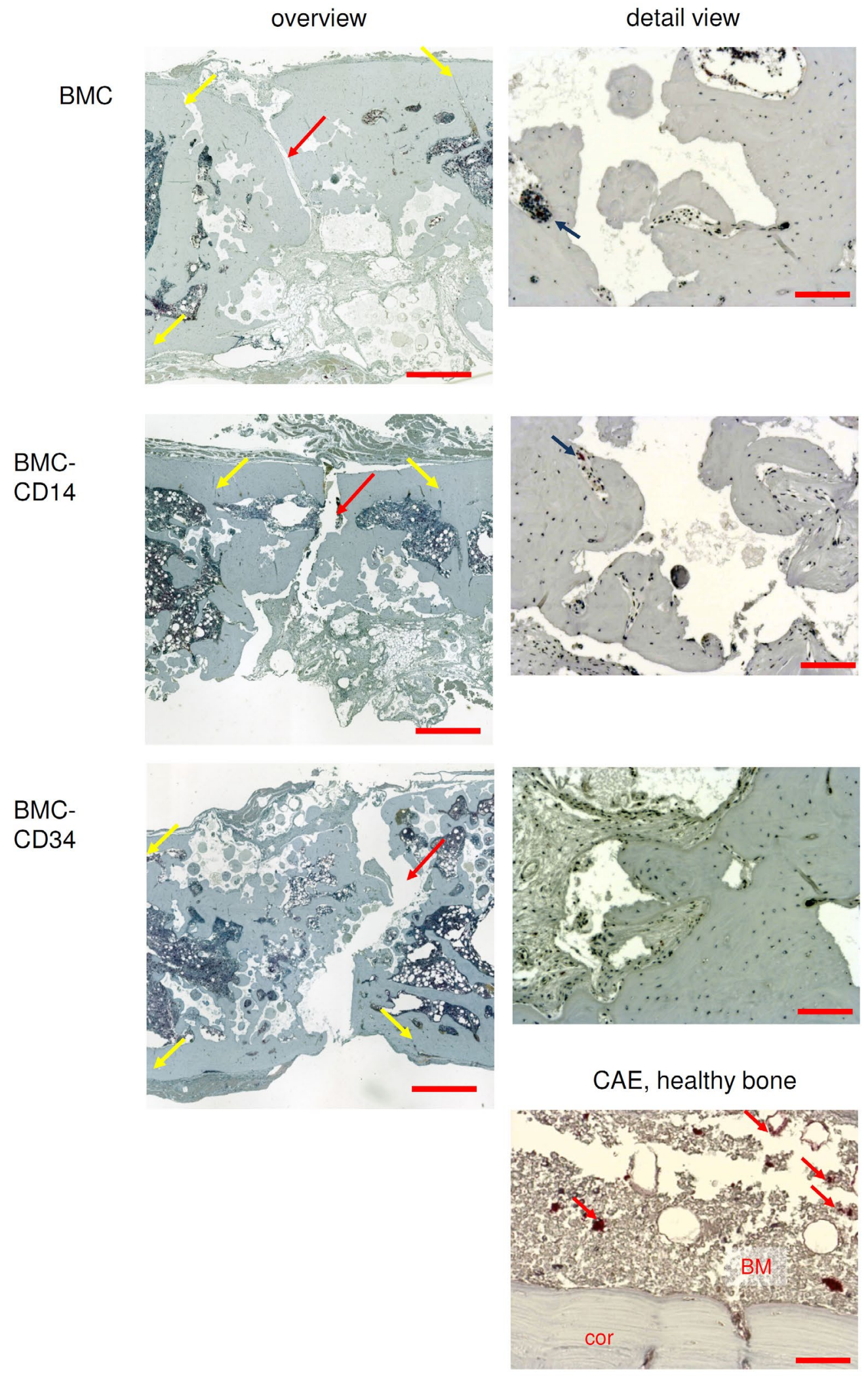

Fig. 5. CAE staining for detection of neutrophil infiltration into the bone defect in animals transplanted with either complete BMC or BMC-CD14 or BMC-CD34, 8 weeks after surgery. No large neutrophil accumulations, which would indicate inflammatory processes, were seen. However, CAE positive cells were observable in the bone marrow (upper row). Part of the images taken at higher magnification showed neutrophils in small number within the defect (lower row). The analysis of healthy bone (lower row, right image) revealed also some neutrophil accumulations within the bone marrow. Blue arrows indicate neutrophil accumulations. Red arrows indicate probable fracture due to prior biomechanical testing. Yellow arrows indicate edges of the original defect. Red bars represent $1 \mathrm{~mm}$ (upper row) and $100 \mu \mathrm{m}$ (lower row). Bone was used for biomechanical testing before histological preparation; thus, fractured areas were visible in all samples. 
Importantly, depletion of CD $34^{+}$cells from BMC had only minor effects on bone healing. 8 weeks after surgery, vascularisation and inflammation in the defect zone were similar in all groups.

Despite increased bone healing parameter in animals receiving non-depleted BMC, complete bone healing, with restoration of the bone structure, including a fully developed bone marrow cavity, was not achieved within the 8-week healing time. This might be explained by a possible impaired bone healing in athymic rats (Liu et al., 2015). Hence, in this animal model, healing time should be increased to reach complete bone healing.

\section{Bone marrow aspirate preparations in bone regeneration}

Bone marrow aspirate concentrate (BMAC) is the most widely used cell therapy treatment, based on autologous bone marrow aspirates, for the treatment of bone defects. The content of platelets and white blood cells is 5-9-fold higher as compared to bone marrow aspirate (Fortier et al., 2010; Jager et al., 2011). In most cases, percutaneous injection of BMAC in patients with atrophic diaphyseal nonunion leads to bone union (Hernigou et al., 2005). In a clinical study by Jager et al. (2011), autologous BMAC, mixed with hydroxyapatite scaffold (HA) or a collagen sponge and transplanted into volumetric bone deficiencies of the femur, foot, hand, humerus, pelvis or tibia, facilitates new bone formation in all patients, with complete healing achieved in the HA group significantly earlier than the collagen group.

The mode of action of BMAC is currently not fully understood and it is proposed, but not yet experimentally tested, that an enriched concentration of MSC provides a cellular source for tissue repair (Hernigou et al., 2005). Other groups posit that leukocytes and platelets might act in a paracrine manner and organise regenerative processes by the release of chemokines and cytokines (Lee et al., 2014; McCarrel and Fortier, 2009).

In contrast to BMAC, BMC preparations are essentially devoid of erythrocytes and polymorphonuclear leukocytes are mostly depleted due to Ficoll ${ }^{\circledR}$ density gradient centrifugation. BMC preparations comprise various cell types, including 3-4 \% of CD34 ${ }^{+}$haematopoietic stem cells, very rare (0.02\%) MSC precursors (Henrich et al., 2015; Seebach et al., 2016) and up to $10 \%$ of monocytes (Sponaas et al., 2015).

The experience regarding the use of $\mathrm{BMC}$ in bone healing is much less extensive. BMC adhere and survive on commercial bone substitutes and their effect on bone healing in a critically-sized femur defect of the rat is significant and, in fact, similar to that exerted by a mixture of precultured myeloid endothelial progenitor cells and marrow stromal cells (Nau et al., 2017; Seebach et al., 2015). Moreover, their safety in the treatment of proximal humerus fractures is proven in a clinical phase I trial (Seebach et al., 2016). Clinical efficacy is also suggested, since, despite an expected dislocation frequency of 30 \% (Geiger et al., 2010; Ockert et al., 2010), all $10 / 10$ patients show primary bone healing. Detailed animal studies indicate that indirect osteo-inductive effects of the therapeutic cells rather than their direct integration into healing bone are responsible for the observed effects on bone regeneration (Seebach et al., 2012). Which cells within the variable cell mix comprising the BMC are responsible remains elusive. The frequent use of the term stem cell therapy for pre-clinical and clinical BMC applications seems to reflect a belief that the therapeutic effects are mediated by the haematopoietic stem cells fraction, but direct evidence is not yet provided. By contrast, the possibility that mature cells, and specifically monocytes, formidable producers of a plethora of trophic factors, mediated these effects was neither considered, nor experimentally explored until now. Seeking to identify the therapeutic agent contained within BMC, subtractive analyses with BMC depleted of haematopoietic stem cells and monocytes was performed.

\section{Monocytes as regenerative cells}

Monocytes and macrophages belong to the first cells recruited to the injured tissues. In addition to their role in phagocytosis, antigen uptake and processing and immune regulation (Geissmann et al., 2010), they fulfil multiple tasks in triggering and regulating initial regenerative responses (Ogle et al., 2016). The beneficial role of monocytes for soft tissue repair is widely analysed. For example, using the ear wound model of the hairless mouse, it is demonstrated that monocytes/macrophages support wound healing, probably by regulating tumour necrosis factor (TNF)- $\alpha$ release (Sander et al., 2009). In comparison to soft tissue healing, bone tissue repair is a more complex process, involving temporally coordinated sequences of different healing events, resulting in a mechanically stable three-dimensional structure without scar formation. However, the early inflammatory phases of bone healing share several features with wound healing, including inflammation and re-vascularisation (Wu et al., 2013). The inflammatory phase during bone healing is characterised by the development of a fracture haematoma, due to bleeding from the surrounding tissues. The haematoma is infiltrated by granulocytes, lymphocytes and monocytes and contains a great variety of cytokines and growth factors, which are released by the immigrated immune cells and degranulating platelets, such as TNF- $\alpha$, interleukin (IL)-1 $\beta$, IL-6, IL-8, IL-10, IL-12, bone morphogenetic protein (BMP)-2, -4 , platelet derived growth factor (PDGF), transforming growth factor (TGF) and vascular endothelial growth factor (VEGF) (Hoff et al., 2017; Schmidt-Bleek et al., 2012). These factors contribute firstly to a continuous recruitment of immune cells, in the sense of a positive feedback loop, and, secondly, to the migration of mesenchymal cells from adjacent bone marrow and periosteum. Next, 
capillary ingrowth ensues and fibrocartilaginous soft callus formation is initiated (Wu et al., 2013). The role of monocytes in the different phases of bone healing has gained increasing attention during recent years. These cells meet multiple requirements for bone healing, including communication with other (regenerative) cells and the surrounding healthy tissue, not only during the initial phase of bone healing (Wu et al., 2013).

Our analysis revealed that most of monocytes within BMC belonged to the CD16- inflammatory subtype, in agreement with the analyses performed by Sponaas et al. (2015). The inflammatory monocyte is the predominant subtype released into circulation after musculoskeletal injury, as shown in mice (Arnold et al., 2007). Hence, BMC therapy provides supplementary pro-inflammatory monocytes to those immigrating actively into the bone defect. The immigrated monocytes probably switch their phenotype to the anti-inflammatory subtype (Arnold et al., 2007) and it is feasible to assume that the monocytes within the transplanted BMC might do the same. However, the differentiation of monocytes into macrophages of the subtypes M1 or M2 depends on local environmental conditions in the affected tissue, as reviewed by Wu et al. (2013). However, this aspect was not addressed in the present study, where it was only possible to speculate on the molecular patterns derived from the monocyte fraction within the transplanted BMC in the various processes involved in bone healing. The beneficial role of monocytes in revascularisation is demonstrated by Barbeck et al. (2016). Monocytes lead to an increased implant bed vascularisation of biphasic calcium phosphate bone substitutes through vessel maturation, but the underlying mechanism is not addressed (Barbeck et al., 2016).

Spiller et al. (2014) show that both the inflammatory and anti-inflammatory macrophage subtypes are capable of supporting revascularisation, albeit through different modes of action. Primary human M1 macrophages secrete the highest levels of potent angiogenic stimulators including VEGF; M2a macrophages secrete the highest levels of PDGF$\mathrm{BB}$, a chemoattractant for stabilising pericytes, and promote anastomosis of sprouting endothelial cells in vitro (Spiller et al., 2014). Despite probable pro-angiogenic effects mediated by monocytes/ macrophages in other settings, differences in vascular density in rats with monocyte-replete vs. monocytedepleted BMC augmentation were not observed. However, our data, generated at week 8, did not preclude the possibility that the monocyte fraction in $\mathrm{BMC}$ might have accelerated vascular regeneration and hence, bone healing, but that these differences in vascularisation did not persist long-term.

Based on the presented results and the general role of monocytes in regenerative processes, it could be reasonable to enrich the $\mathrm{CD} 14^{+}$fraction within the $\mathrm{BMC}$ to improve the healing response. Presumably, those additional $\mathrm{CD}_{14}{ }^{+}$cells will increase bone defect healing to a certain, currently undetermined, optimal CD14 ${ }^{+}$cell concentration. Still, it is important to maintain a balance between regenerative and inflammatory potential of the transplanted cells. Increased inflammatory capacity by excessive CD14 ${ }^{+}$ cells might promote pathological bone regeneration, with an increased risk for enhanced fibrosis and scar formation (Wynn and Vanella, 2016) within the bone defect. The later assumption is underscored by findings of Fukui et al. (2015), who observe impaired bone healing after transplantation of mononuclear cells in a $2 \mathrm{~mm}$ femoral bone defect, as discussed in detail in the next paragraph.

\section{Role of CD34 haematopoietic stem cells in bone healing}

Our results clearly indicated a comparatively negligible role, if any, of $\mathrm{CD} 34^{+}$cells towards the osteo-inductive effects of the BMC. This observation was as important as the identification of CD14 ${ }^{+}$cells as the therapeutic component of the $\mathrm{BMC}$, since it contradicted the widespread equation of BMC therapy with stem cell therapy. Thus, a great body of work assumes that (haematopoietic) stem cell populations mediate the beneficial effects of bonemarrow-aspirate-based cell therapies.

Many groups, ours included, previously assumed, largely based on correlative analyses and prejudice, that BMC equates to stem cell therapy, i.e. that haematopoietic stem cells represent (one of) the therapeutic component(s) within BMC and similar cell sources (Hernigou et al., 2005; Kuroda et al., 2014; Seebach et al., 2015; Seebach et al., 2016). The basis of the assumption is not entirely clear, possibly based on correlative analyses. However, some direct evidence is provided by Fukui et al. (2015), who report a superior potential of $\mathrm{CD}^{+} 4^{+}$cells as compared to total mononuclear cells for healing of non-union following bone fracture. Despite some similarities (same rat strain, same healing time), significant differences can be noted between their and the current approach, including defect size [2 mm (Fukui et al., 2015) vs. $5 \mathrm{~mm}$ ], source of cells [granulocyte monocyte (GM)stimulating-factor-mobilised peripheral blood (PB) $\mathrm{CD}_{4}{ }^{+}$cells and GM-PB mononuclear cells (MNC) (Fukui et al., 2015) vs. BMC], number of transplanted stem cells in the defect $\left[1 \times 10^{5} \mathrm{CD}^{+} 4^{+}\right.$cells (Fukui et al., 2015) vs. ca. $5 \times 10^{3} \mathrm{CD} 34^{+}$cells], MNC dose in the defect $\left[1 \times 10^{7} \mathrm{MNC}\right.$ (Fukui et al., 2015) vs. $1 \times 10^{5}$ ] and type of scaffold [collagen (Fukui et al., 2015) vs. $\beta$-TCP]. The possibility that contaminating monocytes within the CD34-enriched cell dispersions exert the observed effects can be speculated, but clearly the dose of CD $34^{+}$cells in enriched peripheral blood-derived cell dispersions (Fukui et al., 2015), a dose likely not easily achievable in patients, given the 100 -fold lower CD34 ${ }^{+}$cell content in BMC, might also be able to explain the beneficial effects of CD34 ${ }^{+}$ cells. 


\section{Conclusions}

The current study demonstrated that the monocyte fraction within the BMC population exerted the osteo-inductive effects observed during critical size bone defect repair. Likely, a complex cocktail of mediators is involved and future studies might delineate at least some of these factors, so that, in the long run, coating of synthetic bone matrices with growth factor cocktails may obtain similar effects as the autologous BMC-augmented osteo-regenerative fracture treatment.

\section{Acknowledgement}

IM and HB are members of the LOEWE Cell and Gene Therapy Frankfurt faculty funded by Hessian Ministry of Higher Education, Research and the Arts ref.no.: III L 4 518/17.004 (2010).

None of the authors declare a relevant conflict of interest.

\section{References}

Arnold L, Henry A, Poron F, Baba-Amer Y, van Plonquet A, Gherardi RK, Chazaud B (2007) Inflammatory monocytes recruited after skeletal muscle injury switch into antiinflammatory macrophages to support myogenesis. J Exp Med 204: 1057-1069.

Assmus B, Schachinger V, Teupe C, Britten M, Lehmann R, Dobert N, Grunwald F, Aicher A, Urbich C, Martin H, Hoelzer D, Dimmeler S, Zeiher AM (2002) Transplantation of progenitor cells and regeneration enhancement in acute myocardial infarction (TOPCARE-AMI). Circulation 106: 30093017.

Barbeck M, Unger RE, Booms P, Dohle E, Sader RA, Kirkpatrick CJ, Ghanaati S (2016) Monocyte preseeding leads to an increased implant bed vascularization of biphasic calcium phosphate bone substitutes via vessel maturation. J Biomed Mater Res A 104: 2928-2935.

Dawson JI, Oreffo RO (2008) Bridging the regeneration gap: stem cells, biomaterials and clinical translation in bone tissue engineering. Arch Biochem Biophys 473: 124-131.

Fortier LA, Potter HG, Rickey EJ, Schnabel LV, Foo LF, Chong LR, Stokol T, Cheetham J, Nixon AJ (2010) Concentrated bone marrow aspirate improves full-thickness cartilage repair compared with microfracture in the equine model. J Bone Joint Surg Am 92: 1927-1937.

Fukui T, Mifune Y, Matsumoto T, Shoji T, Kawakami Y, Kawamoto A, Ii M, Akimaru H, Kuroda T, Horii M, Yokoyama A, Alev C, Kuroda R, Kurosaka M, Asahara T (2015) Superior potential of CD34positive cells compared to total mononuclear cells for healing of nonunion following bone fracture. Cell Transplant 24: 1379-1393.
Garvey W, Fathi A, Bigelow F, Carpenter B, Jimenez C (1986) Improved movat pentachrome stain. Stain Technol 61: 60-62.

Geiger EV, Maier M, Kelm A, Wutzler S, Seebach C, Marzi I (2010) Functional outcome and complications following PHILOS plate fixation in proximal humeral fractures. Acta Orthop Traumatol Turc 44: 1-6.

Geissmann F, Manz MG, Jung S, Sieweke MH, Merad M, Ley K (2010) Development of monocytes, macrophages, and dendritic cells. Science 327: 656661.

Henrich D, Seebach C, Kaehling C, Scherzed A, Wilhelm K, Tewksbury R, Powerski M, Marzi I (2009) Simultaneous cultivation of human endothelial-like differentiated precursor cells and human marrow stromal cells on beta-tricalcium phosphate. Tissue Eng Part C Methods 15: 551-560.

Henrich D, Verboket R, Schaible A, Kontradowitz K, Oppermann E, Brune JC, Nau C, Meier S, Bonig H, Marzi I, Seebach C (2015) Characterization of bone marrow mononuclear cells on biomaterials for bone tissue engineering in vitro. Biomed Res Int 2015: 762407.

Hernigou P, Poignard A, Beaujean F, Rouard H (2005) Percutaneous autologous bone-marrow grafting for nonunions. Influence of the number and concentration of progenitor cells. J Bone Joint Surg Am 87: 1430-1437.

Hoff P, Gaber T, Strehl C, Jakstadt M, Hoff H, Schmidt-Bleek K, Lang A, Rohner E, Huscher D, Matziolis G, Burmester GR, Schmidmaier G, Perka C, Duda GN, Buttgereit F (2017) A pronounced inflammatory activity characterizes the early fracture healing phase in immunologically restricted patients. Int J Mol Sci 18: E583.

Jager M, Herten M, Fochtmann U, Fischer J, Hernigou P, Zilkens C, Hendrich C, Krauspe R (2011) Bridging the gap: bone marrow aspiration concentrate reduces autologous bone grafting in osseous defects. J Orthop Res 29: 173-180.

Kneser U, Schaefer DJ, Polykandriotis E, Horch RE (2006) Tissue engineering of bone: the reconstructive surgeon's point of view. J Cell Mol Med 10: 7-19.

Kuroda R, Matsumoto T, Kawakami Y, Fukui T, Mifune Y. Kurosaka M (2014) Clinical impact of circulating CD34-positive cells on bone regeneration and healing. Tissue Eng Part B Rev 20: 190-199.

Lee DH, Ryu KJ, Kim JW, Kang KC, Choi YR (2014) Bone marrow aspirate concentrate and plateletrich plasma enhanced bone healing in distraction osteogenesis of the tibia. Clin Orthop Relat Res 472: 3789-3797.

Liu F, Ferreira E, Porter RM, Glatt V, Schinhan M, Shen Z, Randolph MA, Kirker-Head CA, Wehling C, Vrahas MS, Evans CH, Wells JW (2015) Rapid and reliable healing of critical size bone defects with genetically modified sheep muscle. Eur Cell Mater 30: 118-130.

McCarrel T, Fortier L (2009) Temporal growth factor release from platelet-rich plasma, trehalose lyophilized platelets, and bone marrow aspirate and 
their effect on tendon and ligament gene expression. J Orthop Res 27: 1033-1042.

Nau C, Henrich D, Seebach C, Schroder K, Barker JH, Marzi I, Frank J (2017) Tissue engineered vascularized periosteal flap enriched with MSC/EPCs for the treatment of large bone defects in rats. Int J Mol Med 39: 907-917.

Nau C, Henrich D, Seebach C, Schroder K, Fitzsimmons SJ, Hankel S, Barker JH, Marzi I, Frank J (2016) Treatment of large bone defects with a vascularized periosteal flap in combination with biodegradable scaffold seeded with bone marrowderived mononuclear cells: an experimental study in rats. Tissue Eng Part A 22: 133-141.

Ockert B, Braunstein V, Kirchhoff C, Korner M, Kirchhoff S, Kehr K, Mutschler W, Biberthaler P (2010) Monoaxial versus polyaxial screw insertion in angular stable plate fixation of proximal humeral fractures: radiographic analysis of a prospective randomized study. J Trauma 69: 1545-1551.

Ogle ME, Segar CE, Sridhar S, Botchwey EA (2016) Monocytes and macrophages in tissue repair: Implications for immunoregenerative biomaterial design. Exp Biol Med (Maywood) 241: 1084-1097.

Sander AL, Henrich D, Muth CM, Marzi I, Barker JH, Frank JM (2009) In vivo effect of hyperbaric oxygen on wound angiogenesis and epithelialization. Wound Repair Regen 17: 179-184.

Schmidt-Bleek K, Schell H, Schulz N, Hoff P, Perka C, Buttgereit F, Volk HD, Lienau J, Duda GN (2012) Inflammatory phase of bone healing initiates the regenerative healing cascade. Cell Tissue Res 347: 567-573.

Seebach C, Henrich D, Kahling C, Wilhelm K, Tami AE, Alini M, Marzi I (2010) Endothelial progenitor cells and mesenchymal stem cells seeded onto betaTCP granules enhance early vascularization and bone healing in a critical-sized bone defect in rats. Tissue Eng Part A 16: 1961-1970.

Seebach C, Henrich D, Wilhelm K, Barker JH, Marzi I (2012) Endothelial progenitor cells improve directly and indirectly early vascularization of mesenchymal stem cell-driven bone regeneration in a critical bone defect in rats. Cell Transplant 21: 1667-1677.

Seebach C, Henrich D, Schaible A, Relja B, Jugold M, Bonig H, Marzi I (2015) Cell-based therapy by implanted human bone marrow-derived mononuclear cells improved bone healing of large bone defects in rats. Tissue Eng Part A 21: 1565-1578.

Seebach C, Henrich D, Meier S, Nau C, Bonig H, Marzi I (2016) Safety and feasibility of cellbased therapy of autologous bone marrow-derived mononuclear cells in plate-stabilized proximal humeral fractures in humans. J Transl Med 14: 314.

Sorg N, Poppe C, Bunos M, Wingenfeld E, Hummer C, Kramer A, Stock B, Seifried E, Bonig H (2015) Red blood cell depletion from bone marrow and peripheral blood buffy coat: a comparison of two new and three established technologies. Transfusion 55: 1275-1282.
Spiller KL, Anfang RR, Spiller KJ, Ng J, Nakazawa KR, Daulton JW, Vunjak-Novakovic G (2014) The role of macrophage phenotype in vascularization of tissue engineering scaffolds. Biomaterials 35: 4477-4488.

Sponaas AM, Moen SH, Liabakk NB, Feyzi E, Holien T, Kvam S, Groseth LA, Stordal B, Buene G, Espevik T, Waage A, Standal T, Sundan A (2015) The proportion of CD16(+)CD14(dim) monocytes increases with tumor cell load in bone marrow of patients with multiple myeloma. Immun Inflamm Dis 3: 94-102.

Usami K, Mizuno H, Okada K, Narita Y, Aoki M, Kondo T, Mizuno D, Mase J, Nishiguchi H, Kagami H, Ueda M (2009) Composite implantation of mesenchymal stem cells with endothelial progenitor cells enhances tissue-engineered bone formation. J Biomed Mater Res A 90: 730-741.

Wu AC, Raggatt LJ, Alexander KA, Pettit AR (2013). Unraveling macrophage contributions to bone repair. Bonekey Rep 2: 373.

\section{Web Reference}

\section{1. http://imagej.nih.gov/ij/}

\section{Discussion with Reviewers}

Elisabeth Ferreira: Athymic rats, although depleted of $\mathrm{T}$ cells, are able to activate a response against xenografts and the stimulated immune mechanisms can, for example, limit defect healing (Liu et al., 2015). Could an immune response be responsible for the lack of complete healing observed in these athymic rats in response to $\mathrm{BMC}$ implantation?

Authors: Liu et al. (2015) use also a mid-femoral $5 \mathrm{~mm}$ critically-sized bone defect model, where bone defect healing varies from no to complete healing in athymic rats as compared to Fischer F344 rats. Furthermore, the healing response is frequently correlated to the amount of species-specific antibodies directed against the transplant (sheep muscle) (Liu et al., 2015). In our study, a variation in bone defect healing was indeed observable, but by far not as large as compared to the results of Liu et al. (2015), where it ranges from minimal new bone formation to complete bony bridging.

An immune reaction against a transplant is characterised by host cells, such as T lymphocytes (non-functional in athymic rats) and monocytes, infiltrating the graft. Histological signs of acute inflammation, as demonstrated by CAE-staining, or invasion of monocytes after 8 weeks of healing were not find. However, the histological analysis performed was probably not suitable for detecting a subliminal immune reaction. Additionally, the presence of antibodies directed against human antigens was not tested; thus, an immune reaction against the transplanted human cells cannot be excluded. It is important to remember that the 
persistence of human cells in the bone defect was transient and, at the time of analysis, no xenogeneic cells remained, so that any inflammatory response might have abated.

Christopher Niyibizi: The protocol used to obtain $\mathrm{BMC}$, followed by magnetic separation to obtain CD14+enriched cell population, appears tedious for clinical application. Do authors suggest a simpler approach to obtain BMC enriched with a specific sub-population suitable for clinical application, e.g. to heal difficult bone fractures?

Authors: The use of magnetic separation for selective enrichment of cell populations is highly effective, but costly. Alternatively, CD $14^{+}$cells can be enriched by certain centrifugation protocols (Menck et al., 2014, additional reference) and/or by adhesion to plastic (Delirezh et al., 2003, additional reference) and subsequent recovery by enzymatic detachment of the adherent cells. However, the production of cells for therapeutic applications demands certified clean room technologies. The costs for commissioning and maintaining a therapeutic cell production facility are very high and will exceed, by far, those of expensive cell enrichment procedures.

\section{Additional references}

Delirezh N, Shojaeefar E, Parvin P, Asadi B (2013) Comparison the effects of two monocyte isolation methods, plastic adherence and magnetic activated cell sorting methods, on phagocytic activity of generated dendritic cells. Cell J 15: 218-223.

Menck K, Behme D, Pantke M, Reiling N, Binder C, Pukrop T, Klemm F (2014) Isolation of human monocytes by double gradient centrifugation and their differentiation to macrophages in teflon-coated cell culture bags. J Vis Exp 91: e51554.

Editor's note: The Scientific Editor responsible for this paper was Chris Evans. 